\title{
Field Emission Array Cathodes for Electric Propulsion Systems
}

\author{
Colleen M. Marrese* \\ University of Michigan (PEPL) and \\ Jet Propulsion Laboratory \\ Alec D. Gallimore \\ University of Michigan \\ Plasmadynamics and Electric Propulsion Laboratory (PEPL) \\ Ann Arbor, MI 48105 \\ James E. Polk ${ }^{\frac{\hbar}{5}}$ and Keith D. Goodfellow \\ Jet Propulsion Laboratory \\ Pasadena, CA 91109 \\ Kevin L. Jensen \\ Naval Research Laboratory \\ Washington, DC 20375-5347
}

\begin{abstract}
Compatibility issues associated with using field emission array (FEA) cathodes as the electron sources for Hall and ion thrusters were explored and FEA cathode performance is discussed. The cathode environment was characterized using a Faraday probe and NPF probe to determine the local neutral particle pressure and ion flux. A model was used to study the effects of gate voltage, local pressure, and cathode material on cathode lifetime. A sheath model was developed to determine field emission current limitations from a FEA cathode into a virtual anode. Performance comparisons are made between silicon and molybdenum cathodes.
\end{abstract}

\section{Introduction}

The recent thrust towards developing sub- $100 \mathrm{~W}$ electric propulsion systems warrants the development of a cathode to operate on a comparable scale. Hollow cathodes are typically used with higher power Hall thrusters and ion thrusters, however, their propellant and heater requirements place lower limits on their size and power scalability. Filament cathodes are also commonly used with Hall thrusters, however, they require large heater currents, and float to highly negative potentials that reduce thruster efficiency and cathode lifetime. With robust field emitter materials to withstand hostile thruster environments, a field emitter array cathode is a plausible candidate as a low power and efficient electron source for small and micro-propulsion systems.

\footnotetext{
Ph.D. Candidate

"Associate Professor Member AlAA

Copyright ( 1998 by Colleen Marrese. Published by

the American Institute of Aeronautics and Astronautics. Inc. with permission.

Adv. Propulsion Tech. Group Supervisor. Member AIAA

Technical Staff, Member AlAA
}

Field emission array (FEA) cathodes have been under intensive development for use in flat panel displays and devices that require high frequency pulsed electron emission [1]. Field emission tip configuration typically employed is shown in Figure 1; dimensions and materials are processor dependent. Materials most commonly used are silicon and molybdenum, however, coatings have been used to improve robustness of the tips, work functions, and chemical inertness. Electric fields at the emitting tips in excess of $4 \mathrm{E} 7 \mathrm{~V} / \mathrm{cm}$ are required for field emission. Emission currents greater than $1 \mu \mathrm{A} /$ tip can be obtained with operating voltages less than $100 \mathrm{~V}$. Tip and gate aperture radii are on the order of 1 and $100 \mathrm{~nm}$, respectively. Packing densities can be as high as $1 E 8$ tips $/ \mathrm{cm}^{2}$. Emission current densities greater than 1000 $\mathrm{A} / \mathrm{cm}^{2}$ have been achieved with small arrays of tips. 
Typical tip operating environments are $\sim 1 E-9$ Torr after careful conditioning and seasoning $[2,3,4]$. Without such careful preparation, operating voltages are much higher with dangerous start-ups that cause catastrophic tip arcing to the gate electrode that can result in single tip destruction, and sometimes destruction of the entire array $[5]$.

FEAs have demonstrated stable emission in elevated pressure environments when start-up occurs at $\sim 1 \mathrm{E}-9$ Torr and an ambient gas is slowly introduced [6]. Typical pressures in the near cathode region of a $1.3 \mathrm{~kW} \mathrm{Hall}$ thruster are around 1E-5 Torr of xenon. These measurements are discussed in the next section of this report. Spindt et al. [6] showed that tips could run in $\sim 1 \mathrm{E}-5$ Torr of $\mathrm{O}_{2}, \mathrm{Ar}, \mathrm{He}, \mathrm{H}_{2}$, and $\mathrm{N}_{2}$ for hundreds of hours. Tests at Linfield Research Institute (LRI) of single $\mathrm{ZrC}$ and $\mathrm{HfC}$ tips at 1000 s of volts showed that emission continued for several minutes at $1 \mathrm{E}-4$ Torr of $\mathrm{Ar}$ and $\mathrm{O}_{2}$. Although a glow discharge operating mode was attained, the tips were not destroyed during operation for a few minutes in this regime. The results of these experiments in elevated pressure environments is very promising, especially because some of the tips seemed to be undamaged during operation.

A model developed by Brodie [7] to predict sputter rates of the tips, and therefore lifetime, showed that lifetimes should have been less than hours. This model determined tip sputter rates of the emitting area by ions generated between the tip and gate electrode. When used as electron sources in electric propulsion systems, there is an additional population of ions that contributes to tip and cone sputtering. This population of ions originates near the thruster ion beam where charge exchange (CEX) collisions occur between ions and neutrals that are then accelerated from the plasma potential to the cathode potential. This model is discussed later in the report.

The potential of the cathode depends on the local environment. FEA cathodes typically employ a triode configuration with an emitting cone, gate electrode, and physical anode that collects the emitted current. Hall and ion thrusters employ anodes and cathodes separated by a plasma with pressures of $\sim 1 \mathrm{E}-4$ Torr in the ionization regions. In this environment, a virtual anode will collect the emitted current at the cathode sheath boundary. Studies have shown how space-charge effects limit electron emission in field emission triode configurations [1,8-10]. In plasma environments the virtual anode position and potential are variable, depending on the operating conditions, which will determine the emission current limitations.
Space-charge limited current problems have been studied extensively. The Childs-Langmuir relationship describes space-charge limited currents in a vacuum. In the derivation, the current was limited by a zero electric field at the cathode surface because initial electron velocities were negligible. Fay et al.[11] determined emission current limitations in a parallel plate geometry when electrons are emitted with considerable velocities. In that case, positive electric fields at the cathode surface are stable solutions so that virtual cathodes form and grow with emitted electron current to reduce beam current to the anode for a fixed potential between the anode and cathode. Langmuir considered space-charge limitations for parallel plates separated by a plasma, where ions contribute to negative space-charge neutralization to further increase space-charge limited current. He claimed that electron and ion currents were limited in proportion to ion and electron masses when ion and electron initial velocities are negligible, but showed that these currents can increase with non-zero velocities at the sheath boundary [12]. Bohm [13] modeled the sheath near the cathode and determined that for a cathode sheath to be stable, the ions must enter it with non-zero initial velocity, To ensure that potential minima occur only at sheath boundaries for a non-emitting cathode, it was determined that $v_{j}>\left(T_{c} / m_{i}\right)^{\wedge} 1 / 2$. Crawford and Cannara considered the case for space-charge limited emission of a hot cathode into a plasma. They determined a valid velocity range for ions entering the sheath, the velocity being limited by chargeexchange and momentum exchange collisions in presheaths. Prewett and Allen [14] studied the same configuration, and included a criterion derived by Andrews and Allen [15] to construct an analytical expression for the initial energy of ions entering a sheath. Using that expression in the sheath model, they achieved excellent correlation between theory and experiment. The Andrews and Allen criterion was used in the sheath model discussed later in this paper for a configuration where a cathode is strongly emitting into a plasma with initial velocities considerably greater than thermal velocities. as is the case for field emission array cathodes.

Electric propulsion systems typically operate in a configuration where the cathode is floating. A hollow cathode floats $\sim-20 \mathrm{~V}$ with respect to ground in a $1.5 \mathrm{~kW}$ Hall thruster system with a $300 \mathrm{~V}$ anode-cathode voltage difference. They employ extra propellant to generate a plasma at the emitter surface to reduce space-charge effects and the floating potential of the cathode. A reduction in floating potential of the cathode improves the efficiency of the thruster since less voltage is wasted in the cathode fall and a higher voltage is employed by the electric field accelerating the ions to produce thrust. Filament cathodes are inefficient in this way because they float highly 
negative to emit the required current which decreases cathode lifetime and discharge ion energy. It is more crucial that the cathode potential is low with respect to plasma potential when FEA cathodes are used because of the lifetime limitations induced by ions sputtering the tips and gate electrode. It is important that the gate electrode potential is lower than the plasma potential to retard the collection of plasma electrons while the cathode beam electrons escape to the plasma. The relationship between FEA cathode gate potential and emission current limitations in a plasma is discussed in greater detail later in this paper.

In the following sections of this report, the performance issues associated a cathode operating with a Hall thruster are discussed. Measurements taken to characterize the local cathode environment are included in the next section. A model that predicts tip sputter rates is described with results for different cathode configurations and materials, and the issues of electron and ion beam coupling are outlined with a discussion of a model to predict emission current limits for different configurations. This paper ends with a conclusions about the compatibility limitations of FEA cathodes and electric propulsion systems and recommendations for future research.

\section{Cathode environment characterization}

Experiments were conducted to characterize the cathode environment of a Hall thruster that will be used in initial testing with FEA cathodes. These experiments were required to obtain information to be used in cathode performance models and environment simulation for cathode performance evaluations. A laboratory Hall thruster constructed at PEPL with a $70 \mathrm{~mm}$ average diameter of the discharge chamber was used in this investigation. A Faraday button probe provided by JPL was used to measure ion current densities to the region shown in Figure 1, where a FEA cathode will be positioned in future experiments. A neutral particle flux probe (NPF) was provided by PEPL [16] to measure neutral particle pressures in the cathode region. This probe is capable of filtering out ions to obtain measurements of neutral particle pressures only. However, it was determined that the local pressure is primarily from the neutrals, therefore, retarding the ions had virtually no affect on the measured pressures. The first table, Table 1, shows data acquired with the Faraday probe flush with the exit plane of the thruster. Corresponding NPF data is not available. Table 2 shows data taken with both probes when they are positioned about $3 \mathrm{~mm}$ behind the thruster.

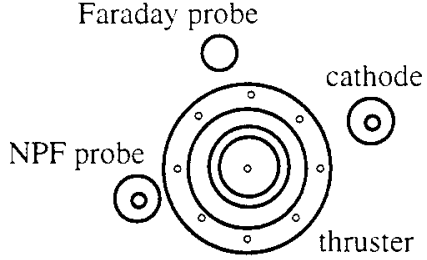

Figure 1. Experimental configuration with the PEPL-70 hollow cathode, NPF, and Faraday Probe.

Table 1. Ion current densities measured by the Faraday probe flush with the physical exit plane of the thruster.

\begin{tabular}{|c|c|c|c|}
\multicolumn{1}{c}{$\mathrm{Id}(\mathrm{A})$} & $\mathrm{Vd}(\mathrm{V})$ & \multicolumn{1}{c}{ Tank (Tor) } & $\mathrm{J}(\mathrm{mA} / \mathrm{cm} 2)$ \\
\hline 1.87 & 259 & $1.10 \mathrm{E}-05$ & 0.010 \\
\hline 1.93 & 300 & $1.10 \mathrm{E}-05$ & 0.010 \\
\hline 2.7 & 298 & $1.30 \mathrm{E}-05$ & 0.013 \\
\hline 3.5 & 298 & $1.50 \mathrm{E}-05$ & 0.018 \\
\hline 3.5 & 300 & $1.70 \mathrm{E}-05$ & 0.014 \\
\hline 4.9 & 300 & $1.90 \mathrm{E}-05$ & 0.020 \\
\hline 4.5 & 300 & $1.90 \mathrm{E}-06$ & 0.019 \\
\hline
\end{tabular}

Table 2. Neutral particle pressures and ion current densities into the cathode region when the probes are about $3 \mathrm{~mm}$ behind the physical exit plane of the thruster.

\begin{tabular}{|c|c|c|c|c|}
$\mathrm{Id}(\mathrm{A})$ & $\mathrm{Vd}(\mathrm{V})$ & \multicolumn{1}{c}{ Tank (Torr) } & \multicolumn{1}{c}{$\mathrm{NPF}(\mathrm{Torr})$} & $\mathrm{J}(\mathrm{mA} / \mathrm{cm} 2)$ \\
\hline 2 & 200 & $9.80 \mathrm{E}-06$ & $8.90 \mathrm{E}-06$ & 0.003 \\
\hline 1.8 & 300 & $1.00 \mathrm{E}-05$ & $9.10 \mathrm{E}-06$ & 0.002 \\
\hline 2.4 & 300 & $1.20 \mathrm{E}-05$ & $9.10 \mathrm{E}-06$ & 0.003 \\
\hline 3.1 & 300 & $1.40 \mathrm{E}-05$ & $1.30 \mathrm{E}-06$ & 0.005 \\
\hline 3.8 & 300 & $1.90 \mathrm{E}-05$ & $1.70 \mathrm{E}-05$ & 0.006 \\
\hline 4.6 & 300 & $1.90 \mathrm{E}-05$ & $1.60 \mathrm{E}-05$ & 0.008 \\
\hline 1.3 & 302 & $8.30 \mathrm{E}-06$ & $2.10 \mathrm{E}-05$ & 0.001 \\
\hline 1.3 & 280 & $8.30 \mathrm{E}-06$ & $2.10 \mathrm{E}-05$ & 0.001 \\
\hline 1.3 & 260 & $8.00 \mathrm{E}-06$ & $2.10 \mathrm{E}-05$ & 0.001 \\
\hline
\end{tabular}

These measurements will be used in the following sections of the report to estimate cathode lifetime. The pressure measured by the NPF probe is strongly influenced by vacuum chamber pressure. Therefore. it should be possible to attain much lower local cathode pressures in chambers with higher pumping speeds which should also increase the cathode lifetime. In the following models, ion current densities of $0.02 \mathrm{~mA} / \mathrm{cm}^{2}$. and local pressures of $1 \mathrm{E}-5$ Torr were used to estimate lower limits in the cathode lifetime model.

\section{Field emission current model}

The analytical model described in this section was developed by Jensen [17] to predict the emission current from a field emission tip and gate electrode structure as shown in Figure 2. 


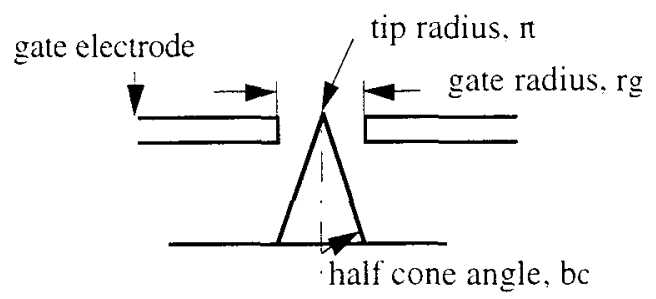

Figure 2. Field emission tip and gate electrode structure.

The field emission tip is commonly modeled with a hyperbolic shape. The field at the apex of the tip can then be approximated by

$$
F_{t i p} \approx \beta_{g} V_{g}
$$

where $\mathrm{V}_{\underline{g}}$ is the voltage on the gate electrode with respect to the emitting cone, the field enhancement factor is

$$
\begin{gathered}
\beta_{g} \approx\left(\frac{\pi}{\ln \left(k r_{g} / r_{t}\right)}-\tan ^{2} \beta_{c}\right) \frac{1}{r_{t}}, \text { and } \\
k \approx \frac{1}{54}\left(86+\frac{r_{g}}{r_{t}}\right) \cot \left(\beta_{c}\right) .
\end{gathered}
$$

The current density is approximated by

$$
J_{F N}(F)=a_{f i} F^{2} \exp \left(-b_{f i n} / F\right),
$$

where the Fowler-Nordheim coefficients are estimated by [18]

$$
\begin{gathered}
a_{f n}=(116 \phi)^{-1} \exp (-0.925 / \sqrt{\phi}) \\
\text { and } b_{f n}=0.642 \phi^{3 / 2} .
\end{gathered}
$$

When the current density is integrated over the surface of the emitter, the tip current is estimated by

$$
I_{\text {tip }}\left(V_{g}\right)=b_{\text {area }} J_{F N}\left(F_{\text {tip }}\right) \text {. }
$$

The area factor, $b_{\text {area }}$ is the ratio between the current from the tip and the current density on axis, and depends upon the magnitude of the gate voltage as

$$
b_{\text {area }}=2 \pi r_{t}^{2} \cos ^{2}\left(\beta_{c}\right)\left(\frac{F_{t i p}}{b_{f i}+\sin ^{2}\left(\beta_{c}\right) F_{t i p}}\right) .
$$

The current emitted from an array of tips can be approximated by

$$
I_{\text {array }}\left(V_{g}\right)=N_{\text {tips }} \sum\left(\Delta s, V_{g}\right) b_{\text {area }}\left(V_{g}\right) J_{F N}\left(F_{\text {tip }}\left(V_{g}\right)\right) \text {, }
$$

where $\Sigma$ is the distribution factor associated with a $\operatorname{spread}(\Delta s)$ in tip radii. The tip radii are distributed according to $r(s)=r_{1}(1+s)$, where $1 \geq s \geq \Delta s$, and $s$ is some spread in tip radius. For a single tip emitting, $s=1$, however, this value decreases with increasing number of tips in an array to decrease the effective emission current per tip. The field along the tip is then $F(s) \approx(1+\cos \theta) F(0)$, where $F(0)=F_{\text {lip }}$.

Approximating the natural $\log$ of $I_{\text {iip }}(s) / I_{\text {iip }}(0)$ as a linear function in $s$ results in

$$
\begin{gathered}
\sum\left(\Delta s, V_{g}\right)=\frac{\exp (\Delta s b)-1}{\Delta s b} ; \\
b=\frac{c_{o} b_{f n}+\left(3 c_{o}+2\right) \beta_{g} V_{g}}{\beta_{g} V_{g}}-\frac{c_{o} \beta_{g} V_{g}}{b_{f n}} \tan ^{2}\left(\beta_{c}\right) \\
\text { where } c_{o}=\frac{1}{\pi \beta_{g} r_{t}}\left(\tan ^{2}\left(\beta_{c}\right)+\beta_{g} r_{t}\right)^{2}-1 .
\end{gathered}
$$

Two configurations were used in the model to predict emission currents. The parameters used in the model are shown in Table 3. One typical cathode configuration was used with work functions for two different emitter materials, molybdenum $(4 \mathrm{eV})$, and silicon $(4.85 \mathrm{eV})$. Predicted emission currents as a function of voltage are shown for single tips in Figure 3 and arrays of tips in Figure 4.

Table 3. Cathode parameters used in the emission current calculations.

\begin{tabular}{|c|c|c|}
\hline \multicolumn{1}{c|}{} & Molybdenum & Silicon \\
\hline$\pi(\mathrm{nm})$ & 500 & 500 \\
\hline$\pi(\mathrm{nm})$ & 4.25 & 4.25 \\
\hline$\beta c\left(^{\circ}\right)$ & 15 & 15 \\
\hline$\phi(\mathrm{eV})$ & 4 & 4.85 \\
\hline$k$ & 4.4 & 4.4 \\
\hline $\mathrm{afn}$ & $1.40 \mathrm{E}-03$ & $1.20 \mathrm{E}-03$ \\
\hline bfn & 5.14 & 6.85 \\
\hline$\Delta s$ & 0.25 & 0.25 \\
\hline Ntips & 10000 & 10000 \\
\hline
\end{tabular}

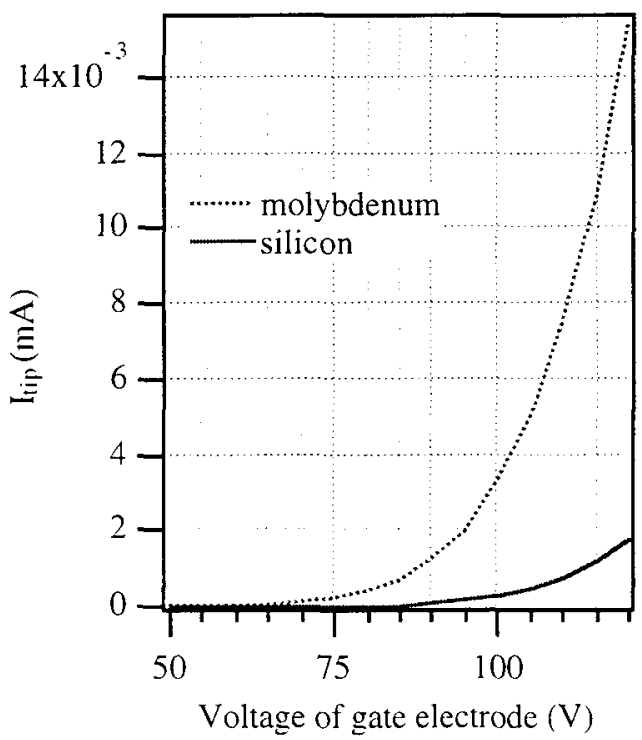

Figure 3. Emission currents from single cathode tips predicted by Jensen's model using cathode configurations described in Table 3. 


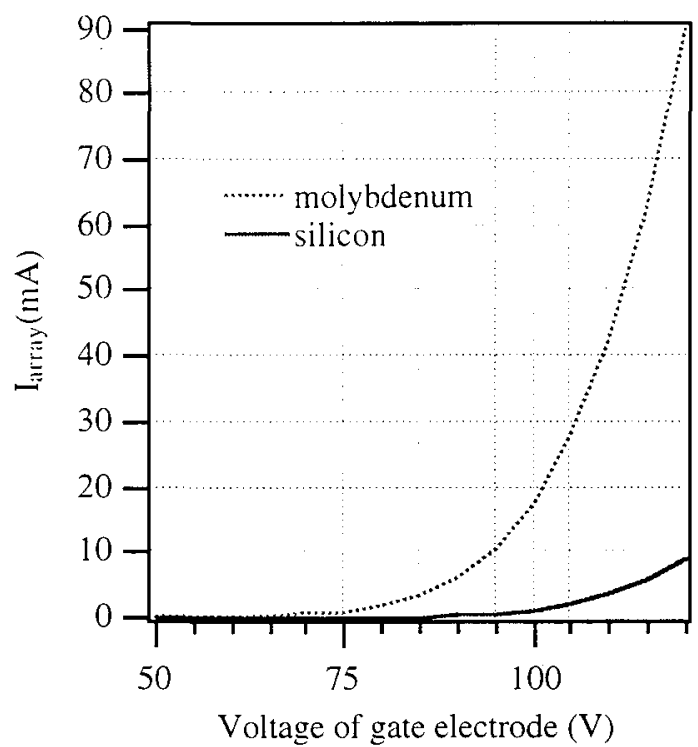

Figure 4. Emission currents from arrays of 10000 cathode tips predicted by Jensen's model using cathode configurations described in Table 3

\section{Cathode lifetime}

The sputter model described in this section was primarily developed by Brodie [19]. This model is capable of estimating sputter rates of tip materials by residual gas ions. It is used here to compare the lifetimes of silicon and molybdenum cathodes in a xenon environment.

If the cathode is considered, as an isolated sphere of radius $r_{i}$ at ground potential, as shown in Figure 5, and the anode as a concentric sphere with radius $r_{a}$, the radial potential distribution on axis of the tip is $\mathrm{V}_{\mathrm{r}}$, and can be roughly approximated by

$$
\frac{V_{r}}{V_{g}}=\left(\frac{r_{t}}{r}-1\right)\left(\frac{r_{t}}{r_{g}}-1\right)^{-1} .
$$

This simple concentric spheres model gives remarkably good results compared to exact predictions obtained by computer solutions of Laplace's equation and geometric boundary conditions [20] because close to the emitting area of the tip, the field lines are radial and fall off inversely as the square of the distance. The Jensen model more accurately predicts the electric field at the tip surface. However, the Brodie model is much simpler and sufficient for predictions of the potential distribution near the tip to determine ion production near the cathode within the accuracy of the sputter yield and ionization cross-section values used.

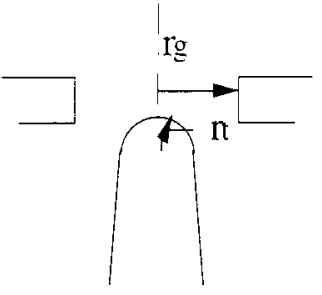

actual

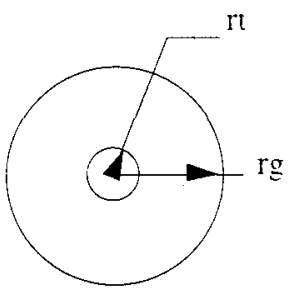

model
Figure 5. The actual cathode configuration, and the configuration used in the model to predict voltage field near the tip and electric field at the tip.

For this analysis, the electric field and current over the emitting area of the tip are assumed to be uniform. Figure 6 shows the density of radial positions used in the calculations and the high voltage gradients near the tip for a $55 \mathrm{~V}$ gate voltage, $4.25 \mathrm{~nm}$ tip radius, and $500 \mathrm{~nm}$ gate aperture. The density of data points was increased until further changes in sputter rate calculations were not observed.

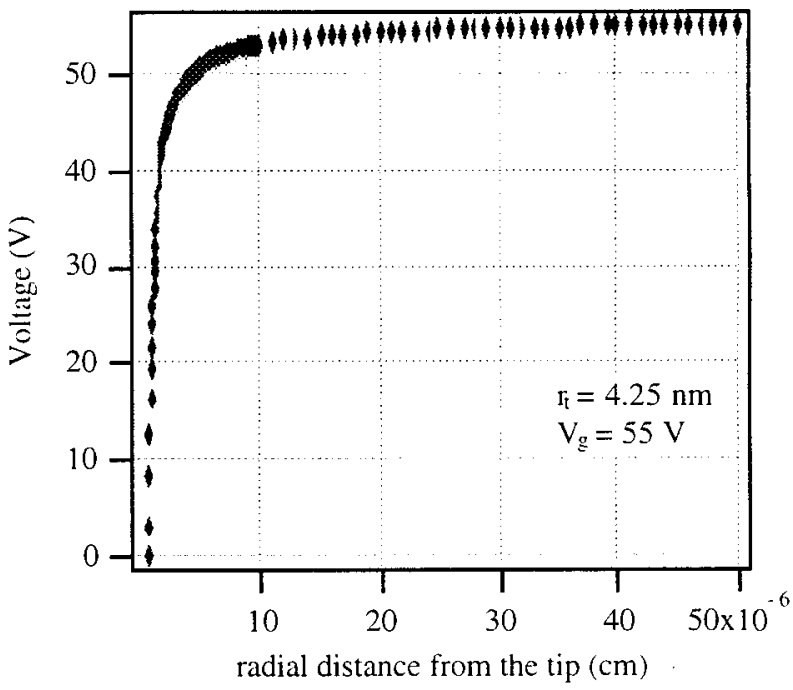

Figure 6. Potential distribution near a tip with a $4.25 \mathrm{~nm}$ radius and $55 \mathrm{~V}$ applied to the gate electrode.

The ion flux to the tip depends on the temperature of the gas and the position that ions are created. If an ion is formed with initial cross radial velocity $v_{1}$ corresponding to a temperature of $V_{1}$ electron volts, then only the ions formed within a radial distance $r_{\mathrm{mi}}$, where

$$
r_{m}=r_{t}\left(\frac{V_{g}}{V_{t}}\right)^{\frac{1}{3}}
$$

will strike the emitting area of the tip. In this model it is assumed that the ion temperature is $0.03 \mathrm{eV}$, and emitting area is within $37^{\circ}$ of the tip axis and is uniformly distributed. 
The significant radial positions are shown in Figure 7. Cathode tip radius is $r_{1}$. The radial positions at which the energy of the electrons reaches the threshold of ionization ( $\mathrm{Vri}=\mathrm{Vi}=$ ionization threshold $)$ is $r_{i}$. The radial position at which, if an ion is formed, it gathers sufficient energy to reach the threshold for sputtering when it strikes the tip surface (Vrs $=V_{s}=$ sputtering threshold) is $r_{s}$. The radial position beyond which the average ion formed will not strike the emitting area of the tip is $r_{m}$.

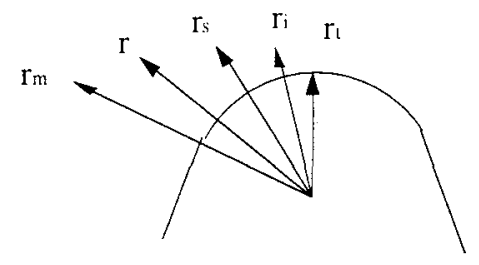

Figure 7. The nomenclature used in the tip sputter rate model.

The number of ions striking the emitting area per second, $\mathrm{n}$, is

$$
n=\int_{r_{i}}^{r_{1}} \frac{I_{e}}{e} N Q\left(V_{r}\right) d r,
$$

and the number of atoms sputtered from the emitting area per second, $\mathrm{n}_{s}$, is given by

$$
n_{s}=\int_{r_{s}}^{r_{m}} \frac{I_{e}}{e} N Q\left(V_{r}\right) Y\left(V_{r}\right) d r
$$

where the field emitted electron current is $I_{c}$ and the number of molecules per $\mathrm{cm}^{3}$ in the vacuum, $\mathrm{N}=$ px3.55E6 molecules $/ \mathrm{cm}^{3}$ ( $\mathrm{p}$ is the pressure in Torr at room temperature). The cross-section for ionization of gas molecules by electrons of energy $V_{r}$ is $Q\left(V_{r}\right)$. The sputtering yield in atoms per ion of energy $V_{r}$ is $Y\left(V_{r}\right)$

The time, $t_{\varepsilon}$, taken to erode a single layer of atoms from the emission area is given by

$$
t_{e}=\frac{2 \pi r_{i}^{2}\left(1-\cos \phi_{t}\right)}{d^{2} n_{s}},
$$

where $d=0.416 \mathrm{~nm}$ for the atomic spacing of evaporated molybdenum and $\phi_{\tau}=37^{\circ}$.

The calculations made by Brodie employed average values of $\mathrm{V}_{\mathrm{r}}$ and then used corresponding $\mathrm{Q}$ and $\mathrm{Y}$ values. In this study, data curves were used for these parameters, and then the integral for $n_{s}$ was evaluated numerically. Sputter rates for xenon ions on molybdenum and silicon targets were used because the thruster environment is primarily xenon. Ionization cross-sections from Brown [21] were used in the calculations. Interpolation was used to determine values between data points. These data are shown in Figure 8. Atomic cross-section is $\pi \mathrm{a}^{2}{ }^{2}$. where. $a_{1}$ is the Bohr radius $(8.7974 \mathrm{E}-9 \mathrm{~cm})$.

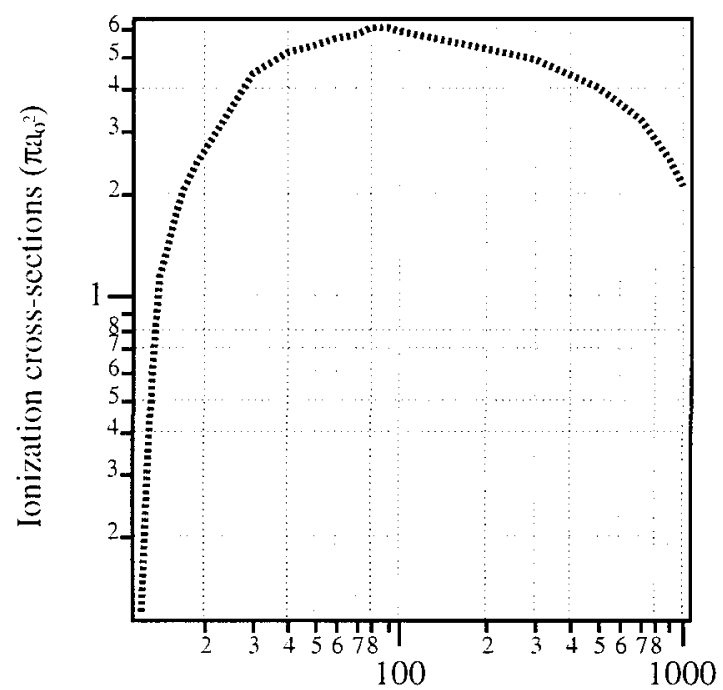

Electron energy (eV)

Figure 8. Electron bombardment ionization cross-sections for xenon.

Sputter yields used in this study for xenon ions bombarding a molybdenum target with a zero degree angle of incidence are shown in Figure 9. These data were generated using the sputter yield model developed by Yamamura et al. [22]. It is interesting to note that sputter yields for xenon ions on a silicon target are significantly lower than for a xenon ions on a molybdenum target.

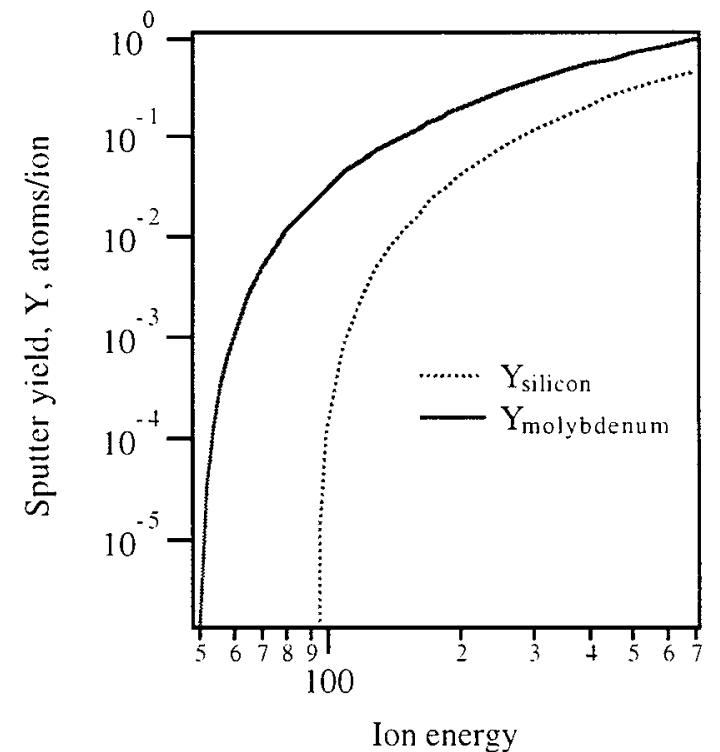

Figure 9. Sputter yield values for xenon ions on molybdenum and silicon targets. 
Lifetime estimates are made for single tips, because the lifetime of an array of cathodes is determined by the lifetime of the single cathode tips. Figure 10 shows estimates of the time to sputter a monolayer of molybdenum atoms off of the tip emitting area, $t_{c}$. If the lifetime is defined by a loss of $10 \mathrm{~nm}$, the tip lifetime can be roughly approximated by $\sim 24 \mathrm{t}_{\mathrm{c}}$. Since $\mathrm{t}_{\mathrm{c}}$ is inversely proportional to pressure and ion current, lifetime with higher currents and pressures can be easily approximated by

$$
t(\text { hrs. })=t_{e} \frac{1}{p(1 E-5 \text { Torr }) I_{e}(\mu A)} .
$$

It is interesting to note that the tip lifetime is very sensitive to operating voltages, therefore motivating the drive to lower values. A reduction in anode voltage from 60 to $55 \mathrm{~V}$ could increase the lifetime by a factor of 1000 .

An additional contribution to the ion flux is made by CEX ions generated by the thruster ions. The ion current density to the cathode region is approximated by 0.02 $\mathrm{mA} / \mathrm{cm}^{2}$, according to the measurements discussed in this report. This ion flux limits the sputter rate per layer of molybdenum to below $0.3 \mathrm{hrs}$. if the gate electrode is at $20 \mathrm{~V}$ below plasma potential. However, the lifetime is increased significantly as the gate voltage increases up to the plasma potential as shown in Figure 10 with gate voltages at the plasma potential and $10 \mathrm{~V}$ below plasma potential. The model results estimate that the effect of the thruster ions on cathode lifetime is to reduce it by an order of magnitude. Preferred gate electrode potentials with respect to plasma potential are discussed in the next section of the report.

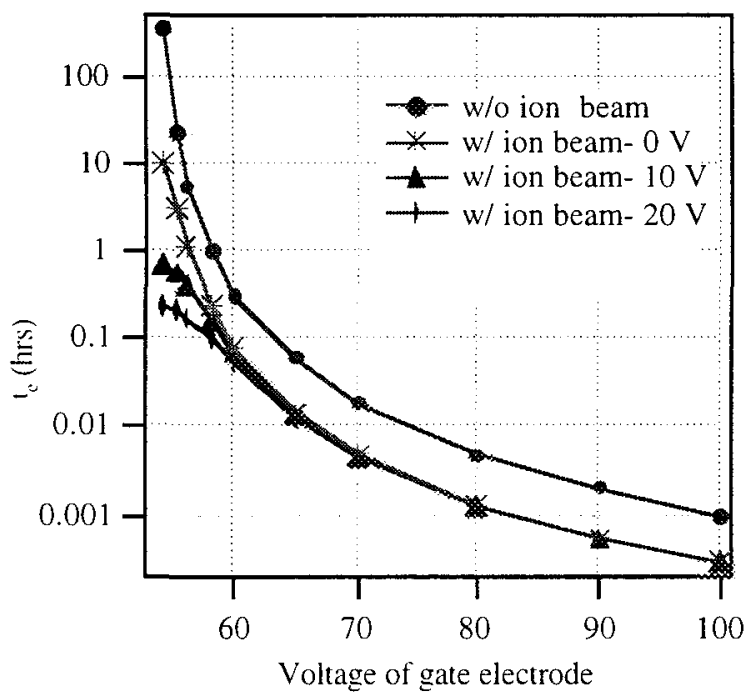

Figure 10. Sputter rates of atomic layers of molybdenum by xenon ions for gate electrode potentials 0,10 , and 20 $\mathrm{V}$ below plasma potential. Ion beam current density is $0.02 \mathrm{~mA} / \mathrm{cm}^{2}$. Xenon pressure is $1 \mathrm{E}-5$ Torr. Tip emission current is $1 \mu \mathrm{A}$ from a tip with a $4.25 \mathrm{~nm}$ radius.

While Figure 10 provides insightful information about the effects of gate voltage and thruster ions on lifetime, it is not a truly accurate representation of lifetime estimates because emission current and gate voltage are coupled parameters. When these parameters are coupled through Jensen's model, more accurate estimates are made for tip lifetimes. Estimates are shown in Figure 11 for silicon cathodes, and in Figure 12 for molybdenum cathodes. Figure 13 shows a comparison of the performance of the different cathode materials in 1E-5 Torr of xenon.

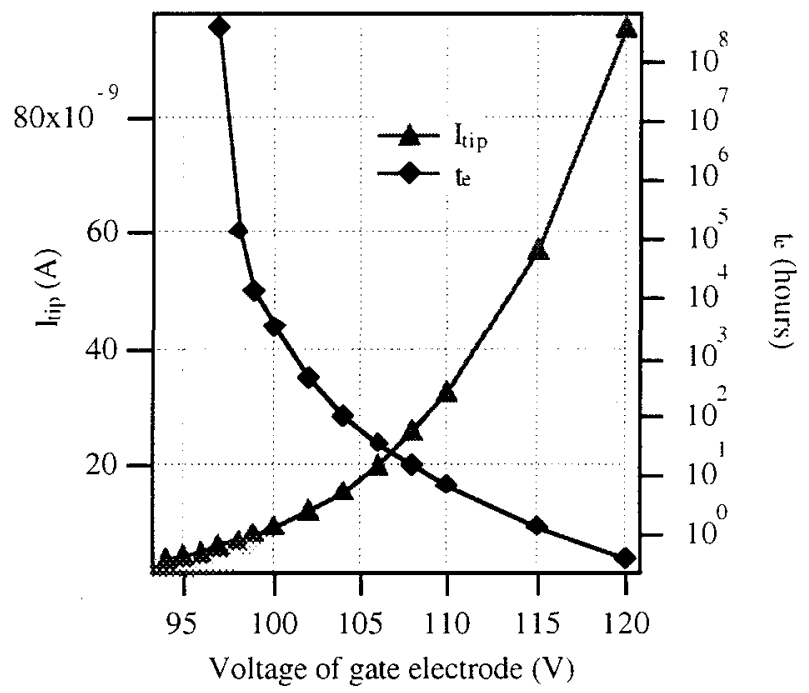

Figure 11. Tip lifetime and emission current for silicon cathodes in 1E-5 Torr of xenon.

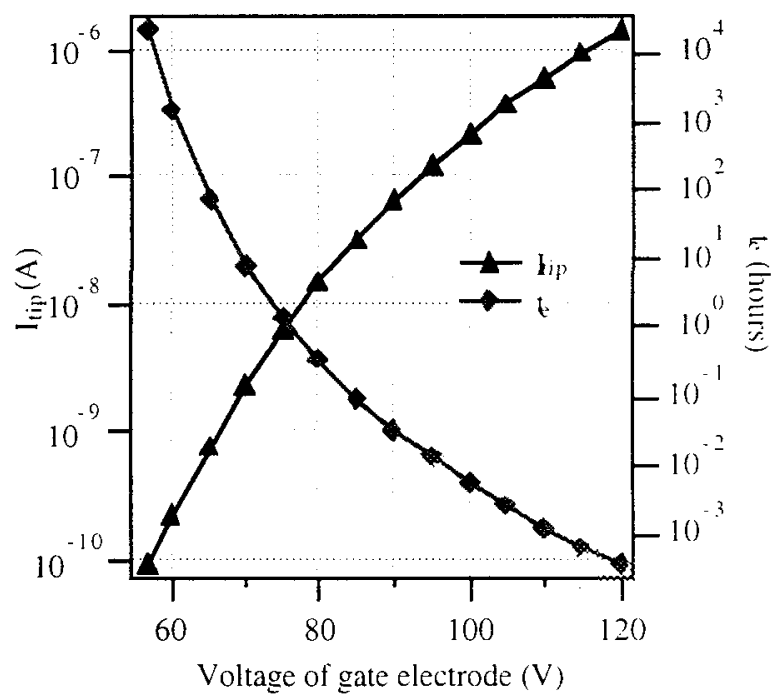

Figure 12. Tip lifetime and emission current for molybdenum cathodes in $1 \mathrm{E}-5$ Torr of xenon. 


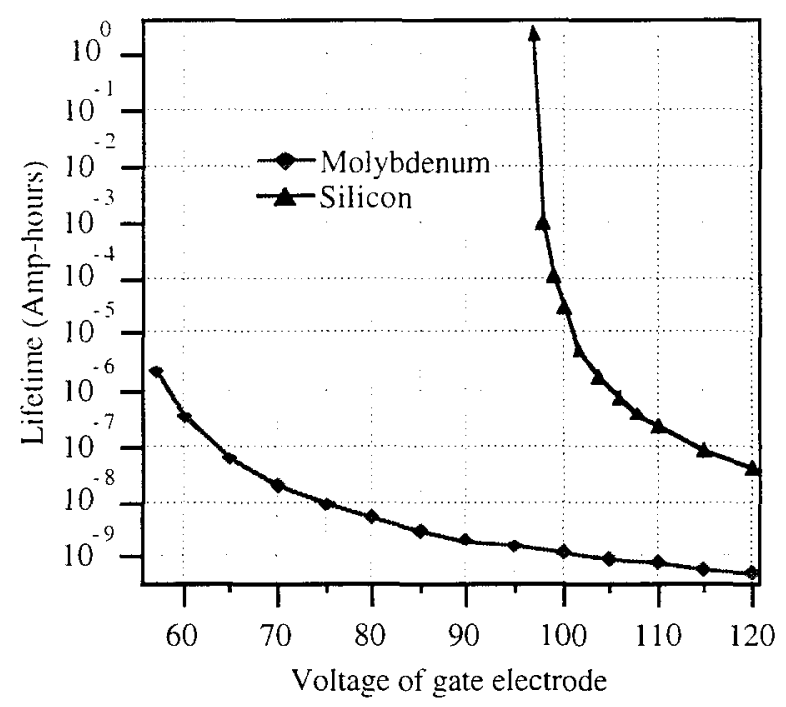

Figure 13. A performance comparison for molybdenum and silicon cathodes in 1E-5 Torr of xenon.

Figures 11, 12, and 13 show that tip lifetimes are incredibly short when cathodes are operating at voltages required to extract currents on the order of $1 \mu \mathrm{A} / \mathrm{tip}$. However, lifetimes in excess of thousands of hours can be obtained at much lower operating currents. It is interesting to note the difference in performance of the two cathode materials. For the same emission current per tip silicon cathodes require much higher voltages, however, because the sputter yields for xenon ions on a silicon target are much lower than for xenon ions on a molybdenum target, silicon cathode lifetimes are at least an order of magnitude higher than the lifetimes of molybdenum cathodes. Therefore, silicon cathodes are recommended in this application. Different results are expected for other ion-target combinations.

Experimental results discussed by Spindt et al. [23] showed that exposure to higher pressure hydrogen environments (1E-6 Torr) for over 10 hours with gate voltages of $\sim 100 \mathrm{~V}$ did not damage molybdenum tips. At these higher pressures, emission currents dropped by an order of magnitude. When the tank pressure returned to UHV emission currents returned to their original levels. Other experiments showed that cathodes operating in air and argon at $1 \mathrm{E}-5$ Torr for hundreds of hours were never damaged. Emission currents decreased during the high pressure exposures but returned to their original values after the tank pressure returned to $\sim 1 E-9$ Torr. Similar results have also been observed for silicon arrays operating in 1E-6 Torr of nitrogen and oxygen [24] at MCNC. It was suggested that current reductions in higher pressure environments are attributed to work function increases due to surface adsorption. Therefore, higher voltages are required to emit a constant current with increasing pressure.

Performance measurements have not yet been taken in xenon environments for silicon or molybdenum cathodes. Experimental results for other ion-target combinations look very promising, while model predictions show cathode lifetimes less than hours for operating voltages around $100 \mathrm{~V}$. The Yamamura model used to predict sputter yields employs a fit parameter to sputter yield measurements that exist only above $100 \mathrm{eV}$. Sputter yields at lower voltages may be overestimated. Sputter yields for ion energies below $100 \mathrm{eV}$ are currently being measured [25]. It also seems likely that there is some process competing with tip sputtering to reduce sputter rates, such as adsorption of residual gas atoms or scattering of ions by local neutrals. These issues are being investigated.

The primary issues governing cathode lifetime are local pressures and operating voltages. To achieve cathode lifetimes in excess of hours, as predicted by the model, low voltages should be employed with small emission currents per tip. If emission currents are $10 \mathrm{nA} / \mathrm{tip}$ in an array of cathodes with $1 \mathrm{E} 9 \mathrm{tips} / \mathrm{cm}^{2}, 100 \mathrm{~mA} / \mathrm{cm}^{2}$ is possible from such an array. The limits on the emission current density into a virtual anode created by the local plasma is discussed in the following section.

\section{Electron emission to virtual anode}

In this section of the report the development of a sheath model is discussed with results to predict the structure of the sheath, and emission current limitations for different cathode operating configurations. The model follows the work by Goodfellow [26]. The following figure describes the problem and some of the parameters used in the model.

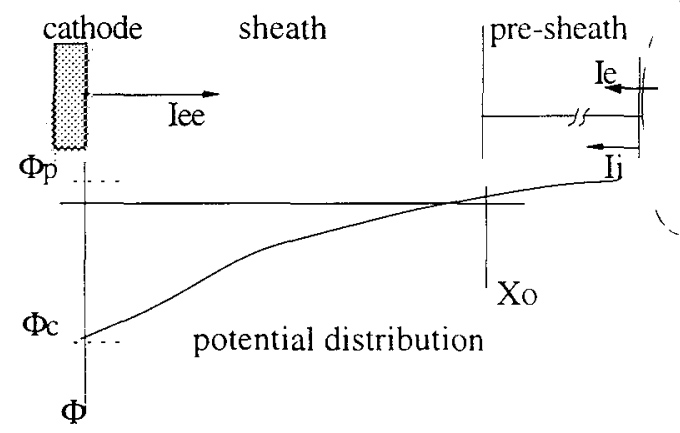

Figure 14. The plasma-cathode configuration being modeled in this study.

It is the objective of this study to determine the potential of the gate electrode with respect to the plasma potential, 
$\mathrm{V}_{\mathrm{c}}$, required to get the desired electron current through the sheath when electrons are emitted with initial energies corresponding to an accelerating voltage, $\mathrm{V}_{\mathrm{g}}$, into an ion beam generated by a Hall thruster. The details of the presheath are not explored, however, it is assumed that the ions are accelerated through the presheath up to some velocity greater than thermal velocities with which they enter the sheath to ensure monatonic potential profiles. It is possible that a virtual cathode will form that will increase the upper limits on the space-charge limited emission current and change the structure. However, it is not certain that this configuration will be stable in the plasma. The investigation into virtual cathode formation is left for future modeling. This model should predict a conservative estimate of the upper limit on the emission current for a given cathode potential.

All potentials represented with $\phi$ are defined with respect to the potential at the sheath boundary where quasineutrality is assumed. The potential distribution in the sheath only is modeled for the 1-D case. Full recombination is assumed for the ions at the cathode surface. Potential magnitudes are used in the input and output of this model for simplicity, however, their true signs are inherent to the following equations. In this case, the 1-D form of Poission's equation is

$$
-\frac{d^{2} \phi}{d x^{2}}=\frac{e}{\varepsilon_{o}}\left(n_{i}-n_{e e}-n_{e}\right)
$$

The continuity and energy equations for the ions and electrons in the sheath are used to determine particle number densities. The ion number density, $\mathrm{n}_{i}$ is

$$
\begin{gathered}
j_{i}=n_{i} e v_{i}=n_{i o} e v_{o}\left(\phi_{o}\right), \\
\frac{1}{2} m_{i} v_{i}^{2}=e\left(\phi+\phi_{o}\right), \\
n_{i}=n_{i o}\left(1+\frac{\phi}{\phi_{o}}\right)^{-\frac{1}{2}} .
\end{gathered}
$$

The accelerating potential of the presheath is $\phi_{0}$. The ion number density at the sheath boundary is $n_{i}$. Plasma electron densities are defined by the Boltzmann relationship for a Maxwellian distribution of electrons

$$
n_{e}=n_{e,} \exp \left(\frac{-e \phi}{k T_{e}}\right) \text {. }
$$

It is assumed that the electrons are Maxwellian with temperature, $T_{c}$, and the number density at the sheath boundary is $n_{i 10}$. The beam electron number densities are defined as

$$
\begin{gathered}
j_{e e}=n_{e e} e v_{e e}, \\
\frac{1}{2} m_{e} v_{e e}^{2}=e\left(V_{g}+\phi_{c}-\phi\right)^{-\frac{1}{2}},
\end{gathered}
$$

$$
n_{e e}=\frac{j_{e e}}{e \sqrt{\frac{2 e}{m_{e}}}}\left(V_{g}+\phi_{c \cdot}-\phi\right)^{-\frac{1}{2}} .
$$

The condition of quasineutrality at the sheath boundary is used to define the ion number density at the sheath boundary in terms of other parameters. At $\phi=0$

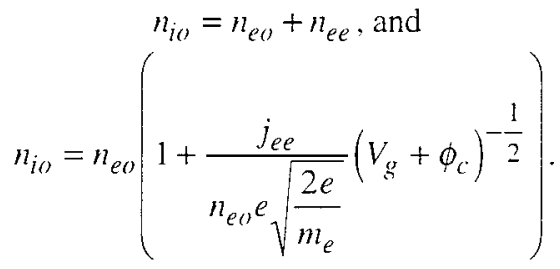

Poisson's equation can then be written as:

$$
\frac{\varepsilon_{o}}{e} \frac{d^{2} \phi}{d x^{2}}=n_{i o}\left(1+\frac{\phi}{\phi_{o}}\right)^{-\frac{1}{2}}-\frac{j_{e e}}{e \sqrt{\frac{2 e}{m_{e}}}}\left(V_{g}+\phi_{c}-\phi\right)^{-\frac{1}{2}}-n_{e v} \exp \left(\frac{-e \phi}{k T_{e}}\right)
$$

The following parameters are used to non-dimensionalize the Poisson equation:

$$
\begin{gathered}
\eta=\frac{e \phi}{k T_{e}}, \xi=\frac{x}{L_{D}}, L_{D}=\left(\frac{\varepsilon_{\theta} k T_{e}}{n_{e v} e^{2}}\right)^{\frac{1}{2}}, j_{e}=n_{e v} e \sqrt{\frac{2 k T_{e}}{m_{e}}}, \\
J_{e e}=\frac{j_{e e}}{j_{e}},
\end{gathered}
$$

where $L_{D}$ is the electronic Debye Length. The nondimensional form of Poisson's equation in this model is

$$
\begin{gathered}
\frac{d^{2} \eta}{d \xi^{2}}=\left(1+J_{e e}\left(\eta_{g}+\eta_{c}\right)^{-\frac{1}{2}}\right)\left(1+\frac{\eta}{\eta_{o}}\right)^{-\frac{1}{2}} \\
-J_{e e}\left(\eta_{g}+\eta_{c}-\eta\right)^{-\frac{1}{2}}-\exp (-\eta) .
\end{gathered}
$$

Integrating Poisson's equation once and applying the first of the following two boundary conditions,

$$
\frac{d \eta}{d \xi}(\eta=0)=0 \text { and } \eta(\xi=0)=\eta_{c}
$$

the electric field in this region is determined to be

$$
\begin{gathered}
\left(\frac{d \eta}{d \xi}\right)^{2}=4 \eta_{i}\left(1+J_{\iota t}\left(\eta_{g}+\eta_{c}\right)^{-\frac{1}{2}}\right)\left(\left(1+\frac{\eta}{\eta_{l}}\right)^{\frac{1}{2}}-1\right) \\
+4 J_{e e}\left(\left(\eta_{g}+\eta_{c}-\eta\right)^{\frac{1}{2}}-\left(\eta_{g}+\eta_{c}\right)^{\frac{1}{2}}\right) \\
+2(\exp (-\eta)-1) .
\end{gathered}
$$

The ion energy at the sheath boundary can be approximated using the criterion derived by Andrews and Allen [15] that

$$
\left.\frac{d}{d \eta}\left(\frac{d^{2} \eta}{d \xi^{2}}\right)\right|_{\eta=0}=0
$$


so that $\eta_{o}=\frac{1+J_{e e}\left(\eta_{g}+\eta_{c}\right)^{-\frac{1}{2}}}{2\left(1-J_{e e}\left(\eta_{g}+\eta_{c}\right)^{-\frac{3}{2}}\right)} \cdot(3)$

Notice that in the limit of zero cathode emission $\eta_{1,} \rightarrow$ $1 / 2$. This result is consistent with the model developed by Bohm [13]. The upper limit on the emission current is being defined when the electric field at the cathode surface becomes zero,

$$
\begin{gathered}
0=4 \eta_{o}\left(1+J_{e e \max }\left(\eta_{g}+\eta_{c}\right)^{-\frac{1}{2}}\right)\left(\left(1+\frac{\eta_{c}}{\eta_{c}}\right)^{\frac{1}{2}}-1\right) \\
+4 J_{e e \max }\left(\left(\eta_{g}\right)^{\frac{1}{2}}-\left(\eta_{g}+\eta_{c}\right)^{\frac{1}{2}}\right) \\
+2\left(\exp \left(-\eta_{c}\right)-1\right) .
\end{gathered}
$$

The maximum emission current possible is

$$
J_{e e_{\max }}=\frac{\eta_{o}\left(\left(1+\frac{\eta_{c}}{\eta_{o}}\right)^{\frac{1}{2}}-1\right)+\frac{1}{2}\left(\exp \left(-\eta_{c}\right)-1\right)}{\eta_{o}\left(\eta_{g}+\eta_{c}\right)^{-\frac{1}{2}}\left(1-\left(1+\frac{\eta_{c}}{\eta_{o}}\right)^{\frac{1}{2}}\right)+\left(\eta_{g}+\eta_{c}\right)^{\frac{1}{2}}-\left(\eta_{g}\right)^{\frac{1}{2}}} \cdot(4)
$$

Solutions to equations 2,3 and 4 are shown in the following figures for some interesting cases. Figure 15 shows the dependence of the maximum emission current on gate and cathode voltages. Figure 16 shows the relationship, predicted by the model, between emission current maximum and cathode voltages. These results show that highly negative cathode potentials are not favorable for strongly emitting cathodes. Therefore, cathodes should not float highly negative to increase electron beam current through the sheath, as observed with filament cathodes in Hall and ion thrusters. Instead, increasing initial electron energies are required to attain high emission currents.

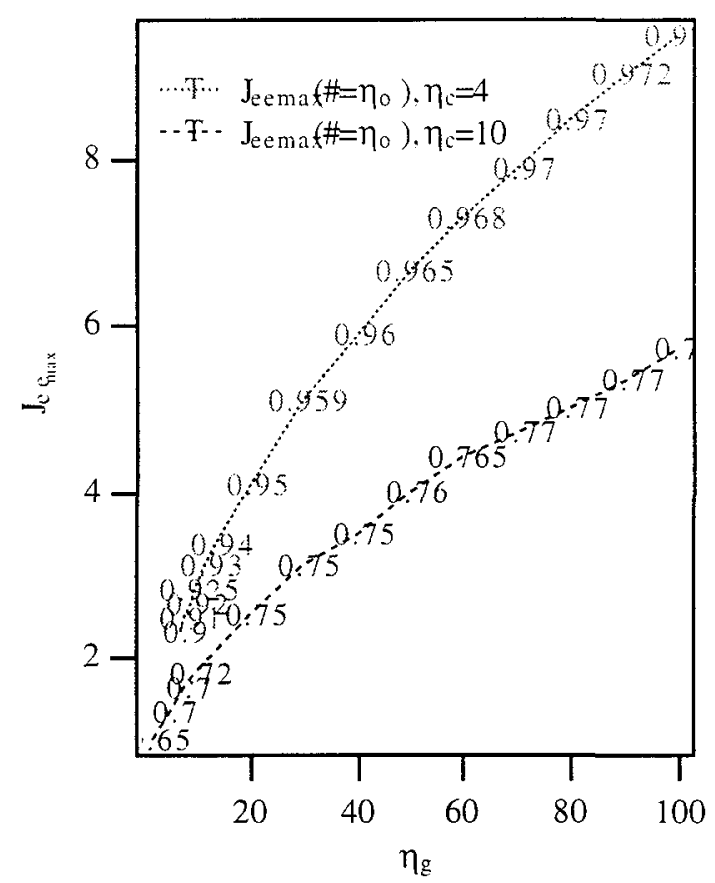

Figure 15. The maximum emission current through the sheath for different gate voltages. The numbers on the curves represent the values of the initial ion energies at the sheath boundary calculated with eqn. 3 at the operating parameters defined.

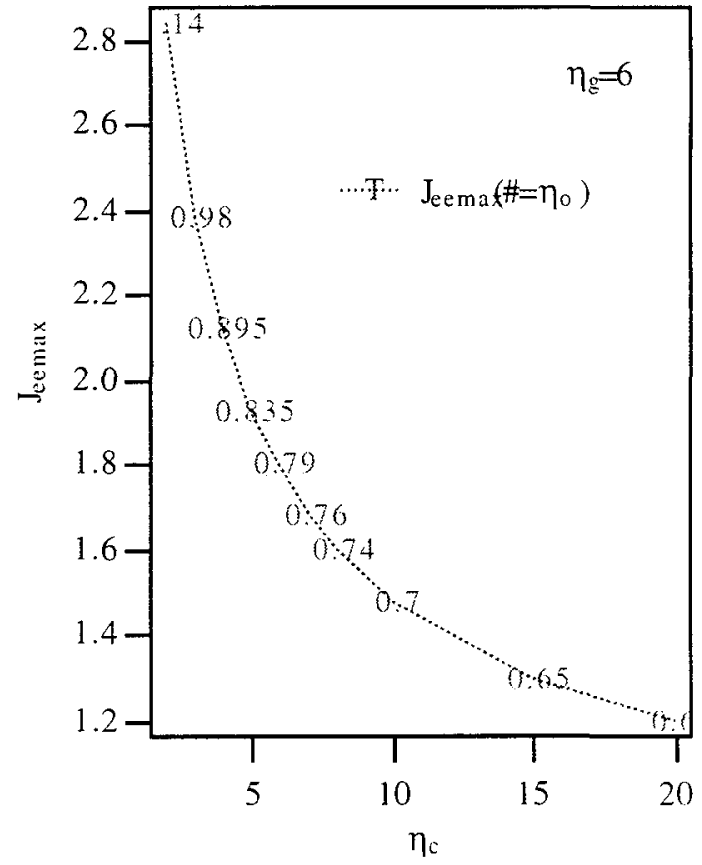

Figure 16. Maximum emission current with different cathode potentials below plasma potentials. The numbers on the curves represent the values of the initial ion energies at the sheath boundary calculated with eqn. 3 at the operating parameters defined. 
The following figures show that potential distributions, electric fields, and charge densities in the sheath for operating regimes of interest. In one particular case of interest $\mathrm{T}_{\mathrm{c}}=5 \mathrm{eV}, \mathrm{n}_{\mathrm{cu}}=8 \mathrm{E} 8 / \mathrm{cm}^{2}$. These results show that for $\phi_{\mathrm{s}}=15 \mathrm{~V}$ and $\mathrm{V}_{\mathrm{g}}=30 \mathrm{~V}$, the upper limit on the emission current, determined by eqs. 3 and 4 , is jee $=2.38 \times 16=38 \mathrm{~mA} / \mathrm{cm}^{2}$. Results are also shown for emission currents much lower than the upper limits. In Figures 18 and 19, model results are shown for a limiting case. Notice the double sheath structure, most obvious in the charge density curve.

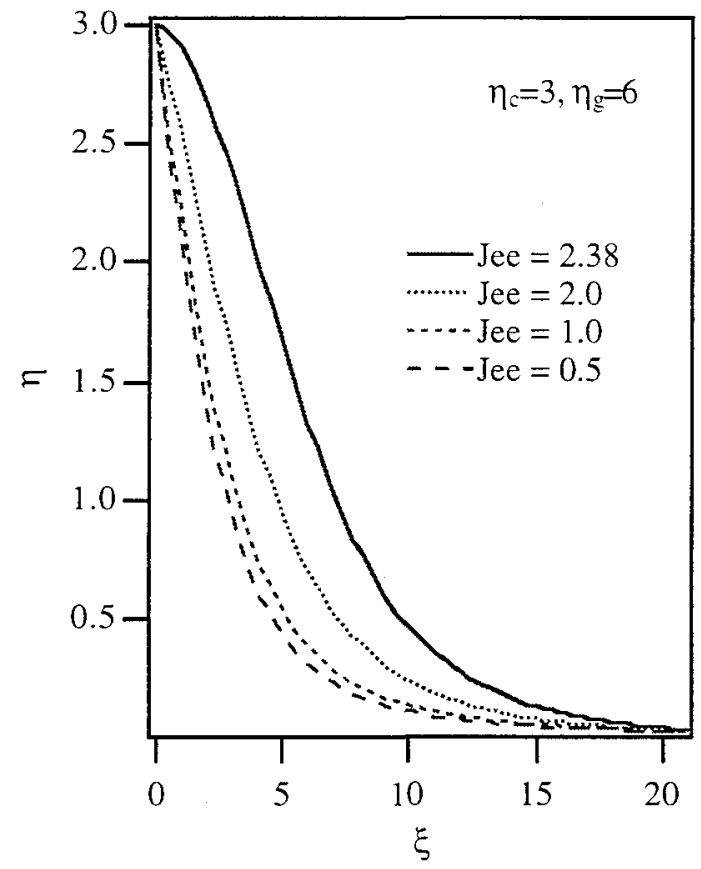

Figure 17. Potential distribution in the cathode sheath for different cathode beam currents.

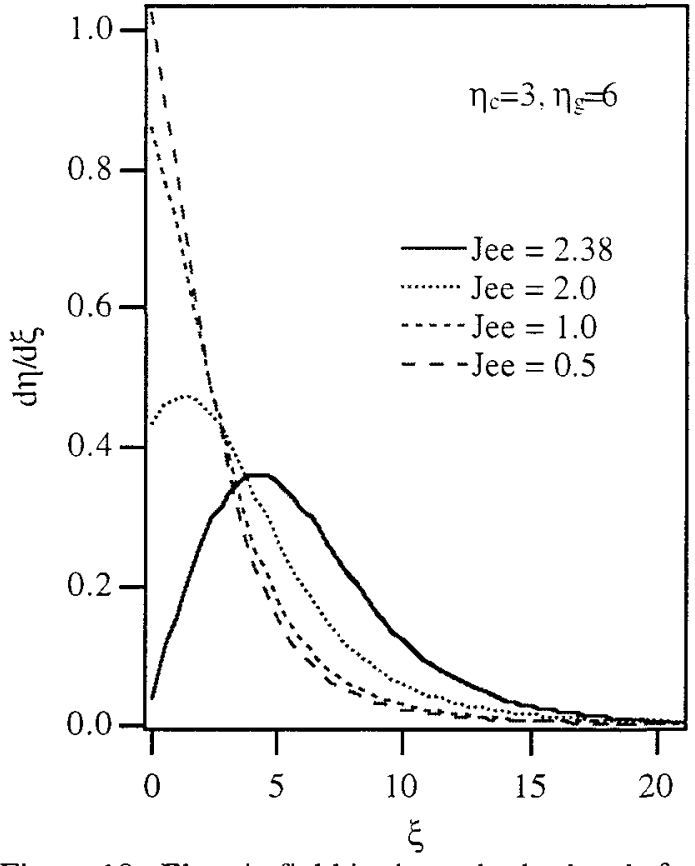

Figure 18. Electric field in the cathode sheath for different cathode beam currents.

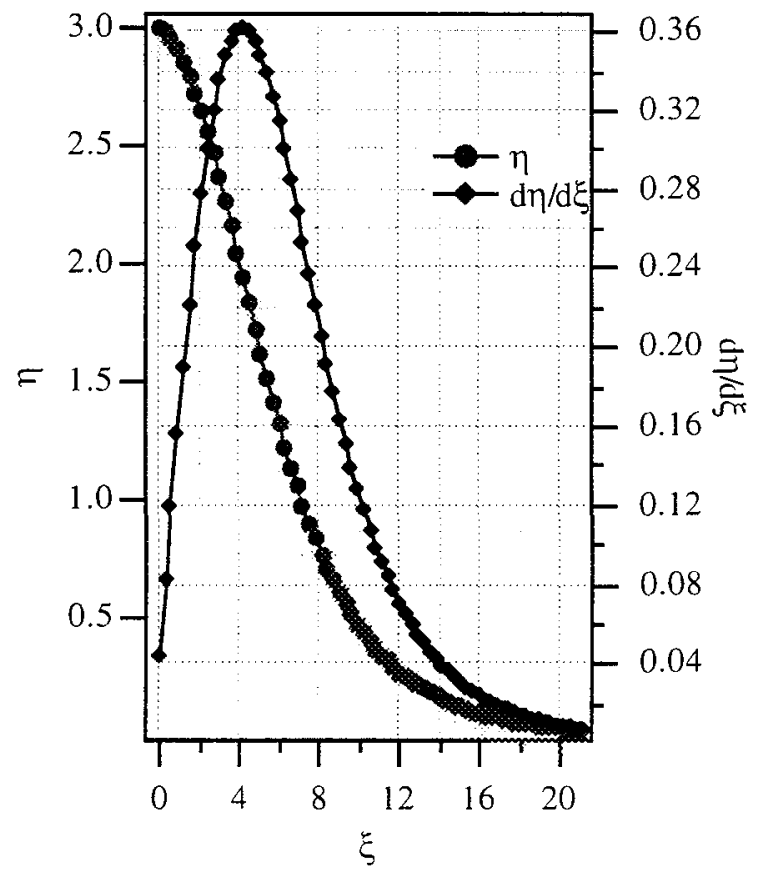

Figure 19. Electric field and potential distribution in the cathode sheath when $\eta_{\mathrm{c}}=3, \eta_{\mathrm{s}}=6$, and $\mathrm{J}_{\mathrm{ec}}=2.38$. 


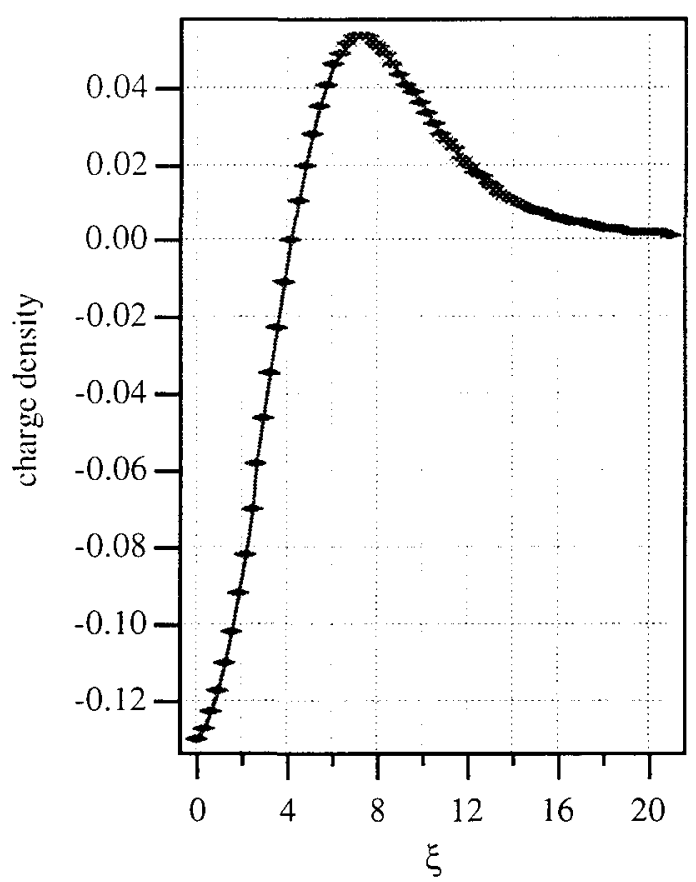

Figure 20. Charge density distribution in the cathode sheath when $\eta_{\mathrm{c}}=3, \eta_{\mathrm{g}}=6$, and $\mathrm{J}_{\mathrm{ec}}=2.38$

The model results are preliminary, revealing some interesting trends. Driving the gate electrode potential highly negative with respect to the plasma potential does not seem to increase the current that can be emitted through the cathode sheath. Increased potential drops in the cathode sheath do not increase the electric field proportionally and reduce the ion number density at the gate electrode to reduce negative space-charge neutralization by the ions. However, increasing the electron energies at the gate electrode does increase the emission current from the cathode. While filament cathodes float highly negative to emit the required current, FEA cathode gate electrodes should be close to the plasma potential while the cathode tip potentials will be biased to voltages greater than $100 \mathrm{~V}$ below the gate voltage to emit current densities around $100 \mathrm{~mA} / \mathrm{cm}^{2}$ in the plasma environments of interest. Current densities greater than $100 \mathrm{~mA} / \mathrm{cm}^{2}$ are desired for use with small and micro ion and Hall thrusters. The following table shows estimates of the upper limits on the cathode beam current predicted by the sheath model for the plasma environment near the thruster where a FEA cathode will be positioned.
Table 4. Upper limits on electron beam currents predicted by the sheath model for the near-cathode environment of a Hall thruster.

\begin{tabular}{|c|c|c|c|c|}
\hline $\mathrm{neo}(/ \mathrm{cm} 3)$ & $\mathrm{Te}(\mathrm{eV})$ & $\mathrm{Vg}(\mathrm{V})$ & $V_{\mathrm{c}}(\mathrm{V})$ & jee $(\mathrm{mA} / \mathrm{cm} 2)$ \\
\hline $8.00 \mathrm{E}+08$ & 5 & 500 & 20 & 160 \\
\hline $8.00 \mathrm{E}+08$ & 5 & 30 & 15 & 38 \\
\hline $8.00 \mathrm{E}+08$ & 5 & 100 & 20 & 64 \\
\hline $8.00 \mathrm{E}+08$ & 1 & 100 & 4 & 80 \\
\hline $8.00 \mathrm{E}+10$ & 1 & 100 & 4 & 8000 \\
\hline & & & \multicolumn{3}{|c}{} \\
\hline
\end{tabular}

The current limitations scale linearly with local charged particle number densities. Near the side of the thruster, electron number densities are estimated at $8 \mathrm{E} 8 / \mathrm{cm}^{2}$, and at the center of the thruster, electron number densities are estimated at $8 \mathrm{E} 10 / \mathrm{cm}^{2}$. Much higher emission current densities can be emitted in the center of the thruster, however, the environment is more hostile and will reduce cathode lifetimes. On solution to this lifetime problem is the use of an ion filter. A retarding electrode can be used between the gate electrode and the thruster to protect the cathode from those ions. If the electrode is used in an einzel lens configuration with two other electrodes, the lens can also provide the function of decoupling the electron energy from the gate voltage to increase the emission current limitations. The details of using a cathode lens and ion repeller (CLAIR) to improve cathode lifetime is discussed by Marrese et al.[27].

\section{Conclusions}

The results of this study show that silicon emitters will have longer lifetimes than molybdenum emitters in the xenon environment created by an ion or Hall thruster. Low gate voltages and small currents per tip are required to achieve lifetimes in excess of hours, while high packing density arrays are required to emit current densities as high as permitted by FEA cathode emission into a virtual anode. Upper limits on the current density can be increased by increasing the energy of the electrons through the gate electrode, or downstream of the gate electrode to preserve cathode lifetime.

According to the model results discussed in this paper, field emission array cathodes are plausible candidates for small and micro ion and Hall thrusters with possibly short lifetime limitations. Lifetimes depend on emission currents and local environments, as shown. The two advantages they offer over hollow and filament cathodes are no propellant and no heater. However, large operating voltages are required which reduces thruster efficiency because they are tied up in the cathode and not used for ion acceleration.

The results presented in this report are preliminary in the research endeavor to determine how to use FEA cathodes 
with electric propulsion systems. Cathode efficiency in elevated xenon pressure environments has not yet been explored, and is the subject of future studies. The sheath model will be expanded into higher dimensions to take into account beam expansion to raise upper limits on the emission currents. The sputter model will incorporate surface adsorption of xenon to determine the effect it has on cathode lifetime.

\section{Acknowledgments}

The authors would like to gratefully acknowledge BMDO (contractor monitor is Jay Polk at JPL), AFOSR (Mitat Birkan), and the National Aeronautics and Space Administration, the sponsors of this research endeavor. The experimental progress reported herein was expedited by the assistance of Bill Thogmartin. Al Owens, Bob Toomath, and Terry Larrow. Modeling advice was contributed by Joe Wang and John Anderson. Advice on the fabrication and operation of field emission devices was contributed by Bill Mackie, Tianbao Xie, Capp Spindt, Stella Pang, Dev Palmer, and Mark Hollis. The authors would also like to thank Brad King and Shane Malone at PEPL the use of the NPF probe that they developed.

\section{References}

1. I. Brodie and P. R. Schwoebel, "Vacuum Microelectronic Devices," Proc. IEEE, 82(7), July 1994.

2. P. R. Schwoebel and C. A. Spindt, "Field-Emitter Array Performance Enhancement Using Hydrogen Glow Discharges," Appl. Phys. Lett. 63(1), 5 July 1993.

3. P. R. Schwoebel. and C. A. Spindt, "Glow Discharge Processing to Enhance Field-Emitter Array Performance," J. Vac. Sci. Technol. B 12(4), Jul/Aug 1994.

4. M. R. Rakhshandehroo and S. W. Pang, "Sharpening Si Field Emitter Tips by Dry Etching and Low Temperature Plasma Oxidation,"J. Vac. Sci. Technol. B 14(6), Nov/Dec 1996.

5. P. R. Schwoebel and I. Brodie, "Surface-science aspects of vacuum microelectronics," J.Vac.Sci. Technol B 13(4), Jul/Aug 1995.

6. C. A. Spindt, C. E. Holland, A. Rosengreen, I. Brodie, "Field-emitter Arrays for Vacuum Microelectronics," IEEE Trans. Electron Dev. 38(10). Oct 1991.

7. I. Brodie, "Bombardment of Field-Emission Cathodes by Positive Ions Formed on the Interelectrode Region," Int.J.Electronics, 1975, 38(4), 541-550.

8. J. P. Barbour, W. W. Dolan, J. K.Trolan, E. E. Martin. W. P. Dyke, "Space-charge Effects in Field Emission," Phys. Rev. 92(1), Oct. 1953.
9. K. L. Jensen, M. A. Kodis. R. A. Murphy, and E. G. Zaidman, "Space-charge Effects on the Current-Voltage Characteristics of Gated Field Emitter Arrays." J. Appl. Phys. 82(2). 15 July 1997.

10.W. A. Anderson. "Role of Space-Charge in Field Emission Cathodes," J. Vac. Sci. Technol. B 11(2). Mat/Apr 1993.

11.C. E. Fay, A. L. Samuel, and W. Shockley, "On the Theory of Space Charge Between Parallel Plane Electrodes," Bell Sysem Technical Journal.

12.I. Langmuir, "The Interaction of Electron and Positive Ion Space Charges in Cathode Sheaths," Phys. Rev. 33, June 1929.

13.D. Bohm, Characteristics of Electrical Discharges in Magnetic Fields, ed. A. Guthrie and R. K. Wakerling, McGraw-Hill Book Co., Inc. 1949.

14.P. D. Prewett and J. E. Allen, "The Double Sheath Associated with a Hot Cathode," Proc. R. Soc. Lond. A. 348, 1976.

15.J. G. Andrews and J. E. Allen, "Theory of a Double Sheath Between two Plasmas," Proc. Roy. Soc. Lond. A. 320, 459-472 (1971).

16.L. B. King and A. D. Gallimore, "Gridded Retarding Pressure Sensor for Ion and Neutral Particle Analysis in Flowing Plasmas," Rev. Sci. Instrum. 68(2), Feb. 1997.

17. K. L. Jensen, "An Analytical Model of an Emissiongated Twstrode Using a Field Emission Array," J. Appl. Phys. 83(12), June 1998.

18.A. Modinos, Field, Thermionic, and Seconday Electron Spectroscopy, Plenum, New York, 1984.

19. I. Brodie, "Bombardment of Field Emission Cathodes by Positive Ions Formed in the Interelectrode Region," Int..Electronics, 1975, 38(4), 541-550.

20.T. E. Everhart, "Simplified Analysis of Point-Cathode Electron Sources," J. Appl.Phys. 38(113), 1967.

21.S. Brown, Basic Data of Plasma Physics, M.I.T. Press 1966.

22. Y. Yamamura, N. Matsunami, and N. Itoh. Radiat. Eff. 71, (1983).

25. O. B. Duchemin. J. R Brophy, C. E. Garner. P. K. Ray, V. Shutthanandan, and M. A. Mantenieks. "A Review of Low Energy Sputtering Theory and Experiments," 25th International Electric Propulsion Conference, August 24-28, 1997. Cleveland. Ohio.

23.C.A. Spindt, C.E. Holland, A. Rosengrcen. I. Brodic. "Field-Emitter Arrays for Vacuum Microelectronics," IEEE Trans. on Elect. Dev., 38(10), Oct. 1991.

24. W. D. Palmer, D. Temple, J. Mancusi, L. Yadon, D. Vellenga, and G. E. McGuire, Emission Current Measurements Under Flat Panel Display Conditions." 25th IEEE ICOPS, Raleigh, NC, June 1998. 
25. O. B. Duchemin, J. R Brophy, C. E. Garner, P. K. Ray, V. Shutthanandan, and M. A. Mantenieks, "A Review of Low Energy Sputtering Theory and Experiments," 25th International Electric Propulsion Conference, August 24-28. 1997. Cleveland, Ohio.

26. K. D. Goodfellow, "A Theoretical and Experimental Investigation of Cathode Processes in Electric Thrusters," Ph.D. dissertation USC 1996.

27. C. M. Marrese, A. D. Gallimore, W. A. Mackie, and D. Evans, "A Cathode to operate in an Oxygen-Rich Environment," paper \#224, Space Technology and International Forum, Albuquerque, NM, Jan. 1997. 